\title{
Diagnostic Accuracy of Endoscopic Ultrasonography Versus the Gold Standard Endoscopic Retrograde Cholangiopancreatography in Detecting Common Bile Duct Stones
}

Mohsin Anwer ${ }^{1}$, Muhammad Sohaib Asghar ${ }^{2}$, Sheeraz Rahman ${ }^{1}$, Shanil Kadir ${ }^{3}$, Farah Yasmin ${ }^{2}$, Dania Mohsin ${ }^{1}$, Rumael Jawed ${ }^{4}$, Gul Muhammad Memon ${ }^{4}$, Uzma Rasheed ${ }^{4}$, Maira Hassan ${ }^{4}$

1. General Surgery, Liaquat National Hospital, Karachi, PAK 2. Internal Medicine, Dow University of Health Sciences, Karachi, PAK 3. Gastroenterology, Liaquat National Hospital, Karachi, PAK 4. Internal Medicine, Liaquat National Hospital, Karachi, PAK

Corresponding author: Muhammad Sohaib Asghar, sohaib_asghar123@hotmail.com

\section{Abstract \\ Background and objectives}

Stone in the biliary tract is one of the most common causes of hospitalization. However, it is difficult to determine the prevalence of gallstones in the general population because they are often asymptomatic. Thus, management lies in the proper clearance of the common bile duct (CBD) along with the removal of the gallbladder, for which it must be diagnosed on time with proper accuracy. Imaging modalities including magnetic resonance cholangiopancreatography (MRCP), endoscopic ultrasound (EUS), and endoscopic retrograde cholangiopancreatography (ERCP) provide true visualization of choledocholithiasis with comparable sensitivities. The gold standard ERCP is an invasive procedure and may cause complications, such as pancreatitis, perforation, and bleeding. EUS is a minimally invasive procedure to assess the biliary tract using high-frequency sound waves. Until now the EUS has not been addressed much in our local tertiary care setups and this study was conducted to evaluate its accuracy in the diagnosis of choledocholithiasis. The objective of our study is to determine the diagnostic accuracy (specificity and sensitivity) of EUS versus ERCP for the diagnosis of choledocholithiasis.

\section{Materials and methods}

This retrospective study was conducted on patients suspected of having choledocholithiasis undergoing both EUS and ERCP based on their history, clinical symptoms, and laboratory test results including upper abdominal pain, deranged liver function enzymes, and a dilated CBD on radiology. EUS was initially performed for the diagnosis of extrahepatic biliary obstruction followed by one or more of the confirmatory criterion standard tests (including ERCP). In order to reduce the chances of passage of stone resulting in negative analysis, only those patients were included in which both procedures were conducted temporally close together (24-72 hours in most instances). The main outcome measures were diagnostic accuracy with

Review began 12/06/2020 Review ended 12/13/2020 Published 12/19/2020

\section{() Copyright 2020}

Anwer et al. This is an open access article distributed under the terms of the Creative Commons Attribution License use, distribution, and reproduction in any medium, provided the original author and source are credited. the help of sensitivity, specificity, positive predictive value (PPV), and negative predictive value (NPV) using a receiver operating characteristic curve. A total of 123 patients met the inclusion criteria via nonprobability consecutive sampling methods.

\section{Results}

The mean age of our study population was $50.30 \pm 13.91$. We included 63 males (51.2\%) and 60 females (48.8\%). The most frequent indication for undergoing diagnostic procedures was deranged liver function tests (67.47\%). The frequent comorbidities reported were hypertension (29.26\%), diabetes (21.95\%), chronic liver disease (16.26\%), and ischemic heart disease (4.87\%). Mean alkaline phosphatase and gamma-glutamyl transferase levels were markedly raised from the baseline in the study population. Post-ERCP complications were also reported in some of the study participants. About 85 patients (69.10\%) were diagnosed with choledocholithiasis among the study participants. The diagnostic accuracy of EUS was compared with ERCP revealed an area under the curve (AUC) of 0.930, standard error of $0.031,95 \%$ confidence interval of $0.868-0.991$, the sensitivity of $89.5 \%$, specificity of $96.5 \%$, positive predictive value of $91.9 \%$, and negative predictive value of $95.3 \%$.

\section{Conclusion}

It is recommended that ERCP can be selectively conducted or excluded in patients with biliary obstruction in case of EUS negative, thus minimizing the complications and morbidity associated with an invasive procedure, with our results showing a comparative diagnostic accuracy of EUS. 
Categories: Radiology, Gastroenterology, General Surgery

Keywords: endoscopic ultrasound (eus), endoscopic retrograde cholangiopancreatography (ercp), gastroenterohepatology, cbd stone, dilated common bile duct, jaundice cholestatic, sensitivity, specificity, receiver operating analysis, biliary obstruction

\section{Introduction}

Stone obstructing the biliary tract is one of the most common diseases resulting in hospitalization. However, it is difficult to determine the prevalence of gallstones in the general population because they are often asymptomatic. Only one-third of gallstones cause symptoms or lead to complications, such as choledocholithiasis (15-20\%) [1]. Thus, management lies in the proper clearance of the common bile duct (CBD) along with the removal of the gallbladder, for which it must be diagnosed on time with proper accuracy. The sensitivity and specificity of imaging techniques are critical for the diagnosis of choledocholithiasis. Imaging techniques should be able to track the presence of small stones in the bile duct. The sensitivity and specificity of imaging techniques are critical for the diagnosis of choledocholithiasis. Imaging techniques should be able to track the presence of small stones in the bile duct. Despite the high sensitivity of transabdominal ultrasound (TUS) for diagnosing cholelithiasis, identifying choledocholithiasis with TUS is difficult at times [1]. Computerized tomography scan has a greater sensitivity than TUS for diagnosing choledocholithiasis, but the level of radiation and cost has limited its use as the first-line tool for diagnosing choledocholithiasis. Non-surgical imaging modalities including magnetic resonance cholangiopancreatography (MRCP), endoscopic ultrasound (EUS), and endoscopic retrograde cholangiopancreatography (ERCP) provide true visualization of choledocholithiasis with comparable sensitivities [2].

The gold standard test is endoscopic retrograde cholangiopancreatography which has the advantage of permitting intervention if a common bile duct stone is present. However, ERCP is invasive and may miss small stones and may cause complications such as pancreatitis, perforation, and bleeding [3]. Thus, it is frequently desirable to confirm the presence of choledocholithiasis before embarking upon intervention for CBD stone removal. Endosonography combines two modalities, namely endoscopic visualization, and highfrequency ultrasound. It is commonly used in the west and we are not much familiar with this modality. Small stones, bile sludge, and even microlithiasis may be detected as compared to other non-invasive procedures. This along with safety and absent radiation makes it a reliable and excellent method for examining the biliary tract [4].

EUS is a minimally invasive procedure to assess digestive (gastrointestinal) and lung diseases. A special endoscope uses high-frequency sound waves to produce detailed images of the lining and walls of the digestive tract, chest, and nearby organs such as the pancreas, liver, and lymph nodes [5]. ERCP is a procedure that directly allows visualization of pancreatic and bile ducts. Until now the EUS has not been addressed much in our local tertiary care setups and this study was done to evaluate its accuracy in the diagnosis of choledocholithiasis. There are certain limitations of EUS like high cost, lack of trained personnel, and limited setups offering this service. Therefore, the objective of our study is to determine the diagnostic accuracy (specificity and sensitivity) of EUS versus ERCP (gold standard) for the diagnosis of choledocholithiasis.

\section{Materials And Methods}

This retrospective study took place in the general surgery and gastroenterology departments of Liaquat National Hospital, a tertiary care hospital having 700 beds with 32 specialty services, located in the heart of city Karachi, Pakistan. Data collection was commenced after approval from the hospital's research and ethics committee. A pool of patients was searched through the hospital's health management information system (HMIS) suspected of having choledocholithiasis undergoing both EUS and ERCP based on their history, clinical symptoms, and laboratory test results including upper abdominal pain, deranged liver function enzymes, and a dilated CBD on plain abdominal ultrasound or other radiological modalities. Collection of data was subsequently done involving choledocholithiasis patients who underwent EUS initially and later, ERCP was performed. The diagnostic accuracy of EUS was determined by comparing it to ERCP (taken as a gold standard) [5]. Data collection included radiological investigations (ultrasound, MRCP, CT scan, EUS, ERCP) and laboratory parameters (descriptive components of liver function tests). In order to reduce the chances of passage of stone resulting in negative analysis, only those patients were included in which both procedures were conducted temporally close together (24-72 hours in most instances). The main outcome measures were diagnostic accuracy with the help of sensitivity, specificity, PPV, and NPV. The sample size was calculated by taking a sensitivity of $96 \%$, specificity of $57 \%$, prevalence of $18.4 \%, d=10 \%$, and a confidence level of $95 \%$. The calculated sample size was 117 patients (Dr. Lin Naing's sample size calculator was used) [6].

The inclusion criteria were all the adult patients undergoing both EUS and ERCP for suspected choledocholithiasis. The exclusion criteria were patients undergoing either EUS or ERCP (only one of them), or patients having malignancy and undergoing ERCP for diagnostic purposes, and patients with a contraindication for ERCP. All those patients who met the inclusion criteria were included in this study via non-probability consecutive sampling methods. All the data was retrieved through the electronic medical record (EMR) system and through the HMIS department and subsequently assembled and analyzed over the 


\section{Cureus}

software IBM Statistical Package for the Social Sciences (SPSS) for Windows, version 25.0 (IBM Corp., Armonk, NY). After descriptive statistics, the receiver operating characteristic curve was generated to determine the sensitivity, specificity, PPV, and NPV of the outcome variable.

\section{Results}

A total of 123 patients met the inclusion criteria. The mean age of our study population was $50.30 \pm 13.91$. This study included 63 males (51.2\%) and 60 females (48.8\%). The most common indication for undergoing diagnostic procedures was deranged liver function tests (67.47\%). Frequent comorbidities reported were hypertension (29.26\%), diabetes (21.95\%), chronic liver disease (16.26\%), and ischemic heart disease (4.87\%). Mean bilirubin, alkaline phosphatase, and gamma-glutamyl transferase levels were significantly raised from the normal range in the study population. Post-ERCP complications reported by the study population are mentioned in Table 1.

\begin{tabular}{|c|c|}
\hline Variables & Mean \pm SD/Frequency (percentage) \\
\hline Mean age & $50.30 \pm 13.91$ \\
\hline \multirow{2}{*}{ Gender } & Males: $63(51.2 \%)$ \\
\hline & Females: 60 (48.8\%) \\
\hline \multirow{2}{*}{ Deranged liver function tests } & Yes: $83(67.47 \%)$ \\
\hline & No: 40 (32.52\%) \\
\hline \multirow{7}{*}{ Comorbidities } & Hypertension: 36 (29.26\%) \\
\hline & Diabetes: 27 (21.95\%) \\
\hline & Chronic liver disease: 20 (16.26\%) \\
\hline & Ischemic heart disease: 6 (4.87\%) \\
\hline & Asthma/Chronic pulmonary disease: 4 (3.25\%) \\
\hline & Chronic kidney disease: 3 (2.43\%) \\
\hline & Autoimmune disease: 1 (0.81\%) \\
\hline \multicolumn{2}{|l|}{ Laboratory values } \\
\hline Total bilirubin (mg/dL) & $2.83 \pm 1.65$ \\
\hline Direct bilirubin (mg/dL) & $1.91 \pm 0.84$ \\
\hline Aspartate aminotransferase (IU/L) & $64.59 \pm 25.87$ \\
\hline Alanine aminotransferase (IU/L) & $53.47 \pm 21.76$ \\
\hline Gamma-glutamyl transferase (IU/L) & $132.85 \pm 86.02$ \\
\hline Alkaline phosphatase (IU/L) & $321.54 \pm 187.91$ \\
\hline \multicolumn{2}{|l|}{ Post ERCP complications } \\
\hline Upper Abdominal pain & $25(20.32 \%)$ \\
\hline Acute pancreatitis (with elevated amylase/lipase) & $5(4.06 \%)$ \\
\hline Elevated liver enzymes (new-onset) & $3(2.43 \%)$ \\
\hline Cholangitis & $2(1.62 \%)$ \\
\hline Intestinal perforation & $1(0.81 \%)$ \\
\hline Post-sphincterotomy bleeding & $1(0.81 \%)$ \\
\hline Septicemia & $1(0.81 \%)$ \\
\hline Death & $0(0.0 \%)$ \\
\hline
\end{tabular}

TABLE 1: Showing baseline characteristics of studied patients $(n=123)$. 


\section{Cureus}

Cutt-off ranges (above-normal levels):

Total bilirubin $(\mathrm{mg} / \mathrm{dL})$ - $>1.0 \mathrm{mg} / \mathrm{dL}$

Direct bilirubin $(\mathrm{mg} / \mathrm{dL})->0.3 \mathrm{mg} / \mathrm{dL}$

Aspartate aminotransferase (IU/L) - >45 IU/L

Alanine aminotransferase (IU/L) - > 45 IU/L

Gamma-glutamyl transferase (IU/L) - >55 IU/L

Alkaline phosphatase (IU/L) - >135 IU/L

ERCP: endoscopic retrograde cholangiopancreatography; SD: standard deviation

About 85 patients (69.10\%) were diagnosed with choledocholithiasis among the study participants. The diagnostic accuracy of EUS was compared with ERCP using the Receiver operating characteristics analysis which revealed an area under the curve (AUC) of 0.930, standard error of $0.031,95 \%$ confidence interval of $0.868-0.991$, sensitivity of $89.5 \%$, specificity of $96.5 \%$, PPV of $91.9 \%$, and NPV of $95.3 \%$, as shown in Figure

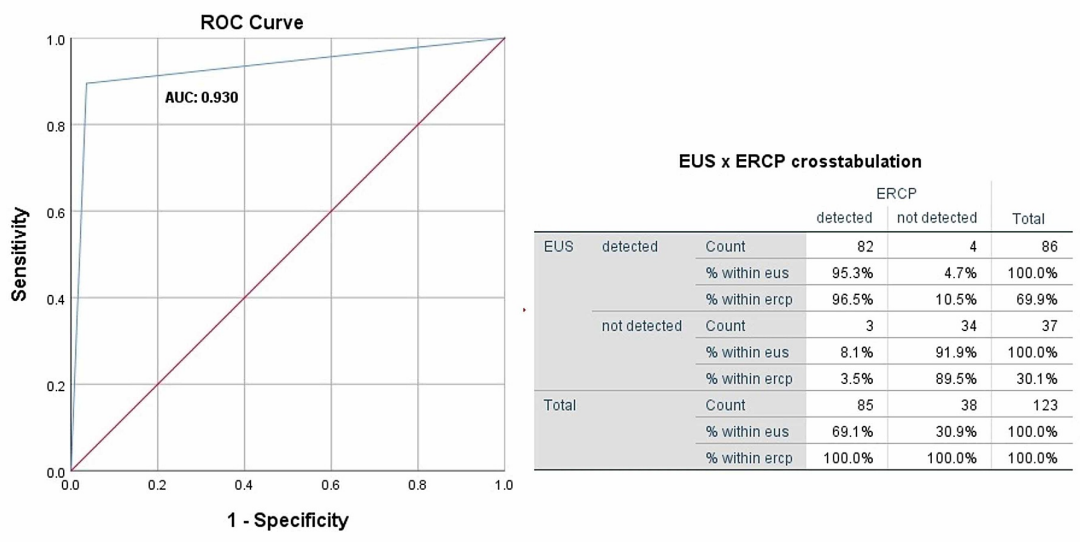

Sensitivity: TP / TP+FN = 89.5\%, Specificity: TR / TR+FP = 96.5\%, PPV: TP $/$ TP+FP $=91.9 \%, \mathrm{NPV}: \mathrm{TN} / \mathrm{FN}+\mathrm{TN}=95.3 \%$

FIGURE 1: ROC curve showing diagnostic accuracy of EUS versus gold standard ERCP.

EUS: endoscopic ultrasound; ERCP: endoscopic retrograde cholangiopancreatography; ROC: receiver operating characteristic; AUC: area under the curve; PPV: positive predictive value; NPV: negative predictive value; TP: true positive; TN: true negative; FP: false positive; FN: false negative

\section{Discussion}

The various literature concluded the diagnostic accuracy of EUS versus other modalities in detecting biliary obstructive disease, as mentioned in Table 2. 


\begin{tabular}{|c|c|c|c|c|c|c|c|}
\hline Author & $\begin{array}{l}\text { Year of } \\
\text { Publication }\end{array}$ & $\begin{array}{l}\text { Number of study } \\
\text { participants }\end{array}$ & $\begin{array}{l}\text { Opposite diagnostic } \\
\text { modality }\end{array}$ & Sensitivity & Specificity & $\begin{array}{l}\text { Positive } \\
\text { predictive } \\
\text { value }\end{array}$ & $\begin{array}{l}\text { Negative } \\
\text { predictive } \\
\text { value }\end{array}$ \\
\hline Makmun et al. [6] & 2017 & 62 & MRCP, ERCP & $96 \%$ & $57 \%$ & $88 \%$ & $80 \%$ \\
\hline $\begin{array}{l}\text { Prachayakul et } \\
\text { al. [7] }\end{array}$ & 2014 & 93 & ERCP & $100 \%$ & $80 \%$ & - & - \\
\hline Tse et al. [8] & 2008 & 2673 & ERCP, IOC & $94 \%$ & $95 \%$ & - & - \\
\hline Karakan et al. [9] & 2008 & 120 & ERCP & $91 \%$ & $100 \%$ & - & - \\
\hline Bansal et al. [10] & 2017 & 170 & ERCP & $100 \%$ & - & - & - \\
\hline $\begin{array}{l}\text { Netinatsunton et } \\
\text { al. [11] }\end{array}$ & 2016 & 141 & ERCP & $97.64 \%$ & $80 \%$ & $97.64 \%$ & $80 \%$ \\
\hline Wang et al. [12] & 2016 & 202 & ERCP & $100 \%$ & $92.88 \%$ & $98.21 \%$ & $100 \%$ \\
\hline Ney et al. [13] & 2005 & 215 & ERCP & $92-96 \%$ & $100 \%$ & - & - \\
\hline Lin and Huang & 2012 & 30 & ERCP & $100 \%$ & $94.7 \%$ & $91.7 \%$ & $100 \%$ \\
\hline Garrow et al. [15] & 2007 & 3532 & ERCP, MRCP, IOC & $88-89 \%$ & $90-94 \%$ & - & - \\
\hline Chak et al. [16] & 1999 & 36 & ERCP, TUS & $91 \%$ & $100 \%$ & $100 \%$ & $95 \%$ \\
\hline Liu et al. [17] & 2001 & 100 & ERCP, TUS & $97 \%$ & $98 \%$ & - & - \\
\hline $\begin{array}{l}\text { Polkowski et al. } \\
\text { [18] }\end{array}$ & 1999 & 52 & $\begin{array}{l}\text { ERCP, CT } \\
\text { cholangiography }\end{array}$ & $91 \%$ & $100 \%$ & - & - \\
\hline $\begin{array}{l}\text { de Ledinghen et } \\
\text { al. [19] }\end{array}$ & 1999 & 43 & MRCP, ERCP & $100 \%$ & $95 \%$ & $90 \%$ & $100 \%$ \\
\hline $\begin{array}{l}\text { Palazzo et al. } \\
\text { [20] }\end{array}$ & 1995 & 422 & ERCP & $94.9 \%$ & $97.8 \%$ & $100 \%$ & $97 \%$ \\
\hline $\begin{array}{l}\text { Aubertin et al. } \\
\text { [21] }\end{array}$ & 1996 & 50 & $10 \mathrm{C}$ & $100^{\circ}$ & $97 \%$ & $92 \%$ & $100^{\circ}$ \\
\hline
\end{tabular}

TABLE 2: Showing the diagnostic accuracy of endoscopic ultrasound fetched from previously studied articles.

ERCP: endoscopic retrograde cholangiopancreatography; MRCP: magnetic resonance cholangiopancreatography; IOC: intraoperative cholangiogram; TUS: transabdominal ultrasound

In our study, we are observing the diagnostic accuracy of EUS versus ERCP which is the gold standard in detecting choledocholithiasis. In multiple studies, the majority of individuals reported a mean age of 55-59 years with the genetic predilection of disease directed towards male gender [11,12], while one study conducted in the same accord reported female gender to be more affected [10]. Majority of individuals presented with upper abdominal pain, jaundice, dilated CBD stones, acute or biliary pancreatitis, ultrasound or CT scan detections suggestive of stone $[11,12]$. The predominant category reported among sufferers of CBD stones was the intermediate-risk category $[10,11]$, while in a study conducted in Taiwan, males suffered more than females and the majority of patients were categorized as high-risk patients. EUS detected CBD stones in a maximum number of high-risk patients as compared to intermediate risk. The majority of patients undergoing EUS did not develop complications. The overall sensitivity, specificity, positive predictive value, negative predictive value, and accuracy were $100 \%, 94.7 \%, 91.7 \%, 100 \%$, and 96.7\%, respectively. CBD stone was positive in $56 \%(9 / 16)$ of the high-risk patients, with one false-positive case and $14.3 \%(2 / 14)$ of the intermediate-risk patients [14].

In a study conducted previously, the occurrence of common bile duct stones had strong gender predilection towards males when compared with females. The majority of sufferers had a mean age of 55 years (18-88 years). Maximum individuals reported abdominal pain (51\%) followed by jaundice (23.4\%), recent cholangitis (25.5\%), and a history of acute pancreatitis (18.4\%); $48.2 \%$ of patients were segregated into the high-risk category while $51.8 \%$ into the intermediate-risk category. The number of stones along with their 
diameters and levels of liver function enzymes were increased in the high-risk group in comparison to the intermediate-risk group. EUS detected CBD stone in 59 out of 68 patients all verified by ERCP, while EUS detected no stones in nine patients out of which seven were verified by ERCP with only two false-negative detections in individuals categorized as high risk. EUS sensitivity, specificity, positive predictive value, and negative predictive value were $96 \%, 100 \%, 100 \%$, and $77 \%$, respectively in the identification of typical bile duct stone in the high-risk category. In the intermediate-risk section, EUS distinguished common bile duct stone in 26 out of 73 individuals while ERCP only verified diagnosis in 24 out of 26 CBD stone positive patients giving two false positives. Conclusive sensitivity, specificity, positive predictive value, and negative predictive value of EUS in demarcating stone in the intermediate-risk category were 96\%, 95.80\%, 92.30\%, and $97.90 \%$, respectively. Patients undergoing EUS did not develop any post-procedure complications, in contrast to which $6.3 \%$ of individuals who underwent ERCP reported post-procedure complications, i.e., mild pancreatitis, bleeding from sphincterotomy, and sphincterotomy associated perforations thus prolonging the hospital stay [11].

In another study, males had an increased frequency of developing CBD stones than females with the majority of individuals having a mean age of 59 years. Patients included in the study with CBD stone had complained of upper abdominal pain, CT and US findings suggestive of CBD stones, bilirubin levels $>$ or equal to $4 \mathrm{mg} / \mathrm{dL}$, dilated CBD stones, and biliary pancreatitis. The majority of patients had a diameter of CBD stone between $0.5 \mathrm{~cm}$ and $1 \mathrm{~cm}$. In this study patients undergoing ERCP developed complications after the procedure including minor ERCP-associated pancreatitis, elevated liver enzymes and bilirubin, septicemia, and post-sphincterotomy bleed. Patients undergoing ERCP did not develop any complications with overall sensitivity, specificity, positive predictive value and negative predictive value of the linear EUS for detecting CBD stones were 100\%, 92.88\%, 98.21\%, and 100\%, respectively [12].

One such study showed a comparison between sensitivity and specificity made on the basis of sizes and diameters of CBD stones with a maximum number of sufferers reporting with a mean size of $5.8 \mathrm{~mm}$ (range: 4.1-8 mm). No case was reported to be missed by EUS and detected by ERCP or vice versa. The sensitivity and specificity of EUS in detecting CBD stones $>4.0 \mathrm{~mm}$ and $>7.0 \mathrm{~mm}$ is $96 \%$ and $100 \%$. The sensitivity of EUS in detecting stone $<4.0 \mathrm{~mm}$ is decreased to $92 \%$ while specificity remains unchanged. In the case of diameter < or equal to $7.0 \mathrm{~mm}$, both sensitivity and specificity of EUS is 100\%. The specificity and sensitivity of ERCP in distinguishing stone diameter $>4.0 \mathrm{~mm}$ is $100 \%$ and $92 \%$, respectively [13]. In a separate study, the mean age of patients was 47 years with female sufferers in the majority contradicting the outcome of multiple studies. The majority of sufferers belonged to the intermediate-risk category. EUS detected stone in $65.9 \%$ of patients, simultaneously these patients underwent ERCP detecting stone in all patients thus confirming the diagnosis of EUS and giving it a sensitivity of $100 \%$. No patient undergoing EUS developed complications. In this study, EUS was found cost-effective when compared with ERCP [10].

For comparing both EUS and ERCP in terms of cost-effectiveness, EUS has increased expenses in the highrisk group and decreased expenses in the intermediate-risk group [11]. EUS was reported to be cost-effective than ERCP in all aspects by another study [10]. Patients undergoing EUS reported no post-procedure complications while those who underwent ERCP developed a variety of post-procedure complications, i.e., mild pancreatitis, bleeding from sphincterotomy, and sphincterotomy-associated perforations thus prolonging the hospital stay, an outcome supported by numerous studies $[10,11,14]$. A study regulated by Petrov et al demonstrates EUS lowering the risk of complications by a relative risk of 0.35 , whereas avoiding ERCP in $67.1 \%$ of patients in their study with an initial EUS evaluation, thereby further reducing the risk of complication by an invasive procedure [22]. In a similar accord, many studies have persuaded the successful use of EUS and ERCP in a single session whenever both procedures are simultaneously indicated in a patient with more than a thousand cases are reported, although not yet common in routine care [23]. One study compared the use of EUS alone versus a combination of EUS and ERCP and concluded that the use of EUS before ERCP showed a significant reduction of procedure time and higher rates of successful procedures [24]. Although a well-documented editorial also highlighted the fact that initial evaluation from EUS strategy vs ERCP alone was effective in the need for eliminating an invasive procedure and was also cost-effective for $60-73 \%$ of patients suffering from choledocholithiasis [25]. Lastly, a review article concluded a sensitivity of EUS as $97 \%$, a specificity of $98 \%$, PPV of $100 \%$, and NPV between $91 \%$ and $100 \%$ [26]. The limitations of the study included retrospective analysis and study participants based on a single-center experience.

\section{Conclusions}

The gold standard for bile duct pre-operative visualization has been ERCP for decades. The non-selective application of ERCP, however, detects CBD stones with less sensitivity in all patients with suspected choledocholithiasis, also exposing them unnecessarily to an invasive procedure and a certain risk of complications. We recommend that ERCP can be selectively conducted or excluded in patients with biliary obstruction in case of EUS negative, thus minimizing the complications and morbidity associated with an invasive procedure. Recent literature has also supported the idea of an initial evaluation by EUS rather than a direct ERCP approach for patients at moderate to high risk of choledocholithiasis, which has been reported to reduce the complications associated with an invasive procedure and to be cost-effective as well by decreasing the need for an ERCP. Our results have shown comparative diagnostic accuracy of EUS in detecting biliary obstructive disease. 


\section{Additional Information \\ Disclosures}

Human subjects: Consent was obtained by all participants in this study. Liaquat National Hospital and Medical College issued approval ref:app\#0574-2020LNH-ERC. The ethical review committee of Liaquat National Hospital and Medical College has approved the study on October 17, 2020. During the study protocol, the researchers maintained the confidentiality of the patients. Animal subjects: All authors have confirmed that this study did not involve animal subjects or tissue. Conflicts of interest: In compliance with the ICMJE uniform disclosure form, all authors declare the following: Payment/services info: All authors have declared that no financial support was received from any organization for the submitted work. Financial relationships: All authors have declared that they have no financial relationships at present or within the previous three years with any organizations that might have an interest in the submitted work. Other relationships: All authors have declared that there are no other relationships or activities that could appear to have influenced the submitted work.

\section{References}

1. Giljaca V, Gurusamy KS, Takawoingi Y, Higgie D, Poropat G, Štimac D, Davidson BR: Endoscopic ultrasound versus magnetic resonance cholangiopancreatography for common bile duct stones. Cochrane Database Syst Rev. 2015, 2:1-77. 10.1002/14651858.CD011549

2. Sousa M, Fernandes S, Proenca L, et al.: Diagnostic yield of endoscopic ultrasonography for dilation of common bile duct of indeterminate cause. Rev Esp Enferm Dig. 2019, 111:757-759. 10.17235/reed.2019.6278/2019

3. Lee TY: Optimal evaluation of suspected choledocholithiasis: does this patient really have choledocholithiasis?. Clin Endosc. 2017, 50:415-416. 10.5946/ce.2017.146

4. Buscarini E, Tansini P, Vallisa D, Zambelli A, Buscarini 1: EUS for suspected choledocholithiasis: do benefits outweigh costs? A prospective, controlled study. Gastrointest Endosc. 2003, 57:510-518. 10.1067/mge.2003.149

5. Angelo TDI, Prochazka V, Holinka M, Zapletalova J: Endosonography versus endoscopic retrograde cholangiopancreatography in diagnosing extrahepatic biliary obstruction. Biomed Pap Med Fac Univ Palacky Olomouc Czech Repub. 2011, 155:339-346. 10.5507/bp.2011.044

6. Makmun D, Fauzi A, Shatri H: Sensitivity and specificity of magnetic resonance cholangiopancreatography versus endoscopic ultrasonography against endoscopic retrograde cholangiopancreatography in diagnosing choledocholithiasis: the Indonesian experience. Clin Endosc. 2017, 50:486-490. 10.5946/ce.2016.159

7. Prachayakul V, Aswakul P, Bhunthumkomol P, Deesomak M: Diagnostic yield of endoscopic ultrasonography in patients with intermediate or high likelihood of choledocholithiasis: a retrospective study from one university-based endoscopy center. BMC Gastroenterol. 2014, 14:1-6. 10.1186/1471-230X14-165

8. Tse F, Liu L, Barkun AN, Armstrong D, Moayyedi P: EUS: a meta-analysis of test performance in suspected choledocholithiasis. Gastrointest Endosc. 2008, 67:235-244. 10.1016/j.gie.2007.09.047

9. Karakan T, Cindoruk M, Alagozlu H, Ergun M, Dumlu S, Unal S: EUS versus endoscopic retrograde cholangiography for patients with intermediate probability of bile duct stones: a prospective randomized trial. Gastrointest Endosc. 2009, 69:244-252. 10.1016/j.gie.2008.05.023

10. Bansal NK, Panda N, Alagammai PL, Narsimhan M, Ardhanari R: Benefits of endoscopic ultrasonography. first strategy in patients with intermediate and high risk for choledocholithiasis. Acta Gastroenterol Latinoam. 2017, 47:252-258.

11. Netinatsunton N, Attasaranya S, Sottisuporn J, Witeerungrot T, Jongboonyanuparp T, Piratvisuth T, Ovartlarnporn B: Comparing cost-effectiveness between endoscopic ultrasound and endoscopic retrograde cholangiopancreatography in diagnosis of common bile duct stone in patients with predefined risks: a study from a developing country. Endosc Ultrasound. 2016, 5:165-172. 10.4103/2303-9027.183971

12. Wang M, He X, Tian C, Li J, Min F, Li HY: The diagnostic accuracy of linear endoscopic ultrasound for evaluating symptoms suggestive of common bile duct stones. Gastroenterol Res Pract. 2016, 2016:1-5. $10.1155 / 2016 / 6957235$

13. Ney MVS, Maluf-Filho F, Sakai P, Zilberstein B, Gama-Rodrigues J, Rosa H: Endoscopic ultrasound versus endoscopic retrograde cholangiography for the diagnosis of choledocholithiasis: the influence of the size of the stone and diameter of the common bile duct. Arq Gastroenterol. 2005, 42:239-243. 10.1590/S000428032005000400009

14. Lin LF, Huang PT: Linear endoscopic ultrasound for clinically suspected bile duct stone . J Chin Med Assoc. 2012, 75:251-254. 10.1016/j.jcma.2012.04.006

15. Garrow D, Miller S, Sinha D, Conway J, Hoffman BJ, Hawes RH, Romagnuolo J: Endoscopic ultrasound: a meta-analysis of test performance in suspected biliary obstruction. Clin Gastroenterol Hepatol. 2007, 5:616623. 10.1016/j.cgh.2007.02.027

16. Chak A, Hawes R, Cooper G, et al.: Prospective assessment of the utility of EUS in the evaluation of gallstone pancreatitis. Gastrointest Endosc. 1999, 49:599-604. 10.1016/s0016-5107(99)70388-3

17. Liu CL, Lo CM, Chan JK, Poon RT, Lam CM, Fan ST, Wong J: Detection of choledocholithiasis by EUS in acute pancreatitis: a prospective evaluation in 100 consecutive patients. Gastrointest Endosc. 2001, 54:325330. 10.1067/mge.2001.117513

18. Polkowski M, Palucki J, Regula J, Tilszer A, Butruk E: Helical computed tomographic cholangiography versus endosonography for suspected bile duct stones: a prospective blinded study in non-jaundiced patients. Gut. 1999, 45:744-749. 10.1136/gut.45.5.744

19. de Ledinghen V, Lecesne R, Raymond JM, et al.: Diagnosis of choledocholithiasis: EUS or magnetic resonance cholangiography? A prospective controlled study. Gastrointest Endosc. 1999, 49:26-31. 10.1016/s0016-5107(99)70441-4 


\section{Cureus}

20. Palazzo L, Girollet PP, Salmeron M, et al.: Value of endoscopic ultrasonography in the diagnosis of common bile duct stones: comparison with surgical exploration and ERCP. Gastrointest Endosc. 1995, 42:225-231. 10.1016/s0016-5107(95)70096-x

21. Aubertin JM, Levoir D, Bouillot JL, et al.: Endoscopic ultrasonography immediately prior to laparoscopic cholecystectomy: a prospective evaluation. Endoscopy. 1996, 28:667-673. 10.1055/s-2007-1005574

22. Petrov MS, Savides TJ: Systematic review of endoscopic ultrasonography versus endoscopic retrograde cholangiopancreatography for suspected choledocholithiasis. Br J Surg. 2009, 96:967-974. 10.1002/bjs.6667

23. Moutinho-Ribeiro P, Peixoto A, Macedo G: Endoscopic retrograde cholangiopancreatography and endoscopic ultrasound: to be one traveler in converging roads. GE Port J Gastroenterol. 2018, 25:138-145. 10.1159/000481537

24. Waheeb AA, El-Khalik MAA, A. El-Sherif AEA, EL-Wassef A, Ali AS: Comparative study between use of endoscopic ultrasound before endoscopic retrograde cholangio pancreatography versus endoscopic retrograde cholangio pancreatography alone. Med J Cairo Univ. 2018, 86:4033-4037. 10.21608/MJCU.2018.62200

25. Chen CC: The efficacy of endoscopic ultrasound for the diagnosis of common bile duct stones as compared to CT, MRCP, and ERCP. J Chin Med Assoc. 2012, 75:301-302. 10.1016/j.jcma.2012.05.002

26. Bergele C, Giovannini M: EUS and common bile duct stones . Ann Gastroenterol. 2004, 17:246-252. 